\title{
Performance and Emission Characteristics of Diesel Engine with the Biodiesel-Acetylene Addition using Dual Fuel Mode
}

\author{
S. Prakash, M. Prabhahar, M. Saravana Kumar
}

\begin{abstract}
This research work investigated the diesel engine performance using $20 \%$ Pongamia grease methyl ester through the effect of different flow rates of acetylene using dual-fuel technique. Acetylene be inducted within the intake various at the flow rates of 1lpm, 2lpm, 3lpm and 4lpm along with air. Initially a test was conducted by diesel fuel along with POME20 on different loads. Then the experiment was carried out with POME20 with different flow rates of acetylene. Addition of acetylene increased the brake thermal efficiency (BTE) among POME20 at all acetylene flow rates on $100 \%$ load. The results showed that the BTE was enhanced via regarding $1-3.4 \%$ at knock-limited acetylene shares at $100 \%$ load. The engine emits higher NOx emission for POME20 without acetylene share and then it is additional improved with the adding up of acetylene shares, while the smoke opacity was reduced by $47 \%$ with acetylene addition at complete load. Here is a decrease in HC as well as $\mathrm{CO}$ emissions were experiential through an acetylene orientation along with POME20. Finally, it is suggested that the poor presentation as well as emissions connected through biodiesel into a diesel engine can be improved through the induction of acetylene with 4 lpm flow rate in the intake various by dual fuel technology.
\end{abstract}

Keywords : Diesel engine, Pongamia methyl ester, Acetylene, duel fuel, Emission, Performance.

\section{INTRODUCTION}

Over the past three decades, the industrial revolution and increased population have resulted in increased fossil fuel consumption. In general, the petroleum-based fuels were used for internal combustion (IC) engines. Diesel engines are commonly used for transport, power fix and agricultural machineries outstanding to their superior power output as well as consistent performance at all loads. Conservative hydrocarbon fuels worn by these engines result in highly harmful pollutants such as carbon dioxide (CO2), nitrogen oxides (NOx), hydrocarbon (HC), sulfur oxides (SOx carbon monoxide (CO) as well as particulates [1 ]. To overcome these problems, the researchers search an option fuels for

Revised Manuscript Received on December 11, 2019

* Correspondence Author

S. Prakash, Research Scholar, Department of Mechanical Engineering, Aarupadai Veedu Institute of Technology, Vinayaka Mission Research Foundation, Chennai, India. Email: Prakash.mech94@gmail.com

Dr. M. Prabhahar, Professor, Department of Mechanical Engineering, Aarupadai Veedu Institute of Technology, Vinayaka Mission Research Foundation, Chennai, India. Email: mprabhahar@gmail.com

M. Saravana Kumar, Research Scholar, Department of Mechanical Engineering, Aarupadai Veedu Institute of Technology, Vinayaka Mission Research Foundation, Chennai, India. Email: sarov003@gmail.com diesel engines similar to biomass, biofuel, alchohol and gaseous fuels.

Vegetable oil is one of the choices to diesel fuel which have similar psychochemical properties to diesel fuel. Elevated thickness of vegetable oils means ineffective pumping as well as sprays arrangement. For that reason, air along with fuel is not varied properly and leads to incomplete combustion. The squat instability of vegetable oils also results in lots of carbon deposits, injector coking as well as piston ring sticking $[2,3]$ Biodiesel making from non-edible oil sources like as Pongamia oil methyl ester can be regarded as a healthy option. Vegetable oil is one of the option renewable fuel resources which include related burning individuality as well as psychochemical possessions in the direction of the petroleum diesel. The thickness of vegetable oil is condensed by chemical reaction called transesterification process. Transesterification process is used in the being there of $\mathrm{NaOH}$ or $\mathrm{KOH}$ as means to transform vegetable oil into biodiesel with the assistance of alcohol. The physic-chemical characteristics of biodiesel are similar to diesel as well as it is suitable as fuel intended for diesel engine [4, 5].

Biodiesel has several benefits including less sulfur, more oxygen, higher cetane value, biodegradable, and emits less emissions evaluated to diesel. In accumulation, biodiesel fuels have improved lubrication and a higher ignition high temperature that is inflammable and has huge potential as a diesel engine fuel $[6,7]$. Biodiesel within engines contribute abridged emissions of $\mathrm{CO}, \mathrm{HC}, \mathrm{PM}$ as well as smoke emission while emitting greater emissions of NOx. Prabhu et al [8] studied the presentation as well as production behaviors of a diesel engine with neem lubricate biodiesel blends. Their findings showed so as to NOME and its diesel blends have condensed productions of smoke, carbon monoxide (CO) along with enhanced emissions of NOx emissions. Rajan along with Senthilkumar [9] examined the recital as well as production of a diesel engine through Jatropha biodiesel through inside plane piston. It is found that the BTE was comparable with diesel fuel and the CO along with smoke productions were reduced except NOx releases.

It is possible to use gaseous petroleum such because liquefied petroleum gas (LPG), compressed natural gas $(\mathrm{CNG})$, hydrogen gas, as well as acetylene gas in a diesel engine by as double oil style. Dual fuel process in CI engine produces a decrease in smoke
Engineering \& Sciences Publication 
emission with an increased presentation. Numerous research works has been reported in the recent past on dual oil in compression ignition (CI) engines includes the use of various fuels, induction as well as injection processes [10-14].

Sharma et al [13] deliberate the recital of a diesel engine with acetylene diesel oil as duel oil mode and the results showed higher NOx and lower smoke release as well as a better brake thermal capability next to maximum loads. Elnajjar et al [14] investigated the effect of LPG with dissimilar Propane in the direction of Butane volume relation work of art on the recital of dual oil engine. The results indicated that dissimilar LPG fuel work of art has negligible consequence on the engine thermal competence. Vijayabalan and Nagarajan [15] carried out the test in a diesel engine running by Jatropha oil as well as LPG as dual fuel operation. The results revealed that there is a decrease in NOx as well as smoke emissions throughout the load variety, through elevated thermal brake competence. Lakshmanan and Nagarajan [16] carried out the experiment in a diesel engine inducting acetylene through timed manifold inoculation technique, through diesel as the primary fuel and various flow rates of acetylene such as $110 \mathrm{~g} / \mathrm{s}, 180 \mathrm{~g} / \mathrm{s}$ in addition $240 \mathrm{~g} / \mathrm{s}$. The outcome demonstrate that the BTE was closer to that of diesel fuel and $\mathrm{NOx}, \mathrm{HC}$, in addition to $\mathrm{CO}$ releases were reduced appropriate to lean procedure, with marginal increases during burn releases. It is expected so as to up to 24 percent substitution of acetylene with a reduction in emissions was feasible.

Lakshamanan and Nagarajan [17] studied the performance as well as releases quality of diesel engine through inducting the acetylene into the intake system at the fixed flow rate of $31 \mathrm{pm}$. It is noticed to the diesel engine by dual oil form gives a smaller thermal efficiency as well as smoke production at filled weight. But the $\mathrm{CO}$ as well as $\mathrm{HC}$ emissions are related to the baseline diesel oil. Due to the accelerated burning of acetylene with diesel significantly increases the formations of NOx releases.

Mahla et al. [18] carried out experiment on top of the diesel engine through acetylene in addition to mixed through diethyl ether on a speed of $121 \mathrm{pm}$ addicted to the inlet organization. The acetylene as well as Di Ethyl Ether (DEE) blend showed an improved thermal efficiency price to diesel oil. Ashok et al.[19 ] investigated the capability of acetylene along with EGR in petrol engine and confirmed that emissions are drastically reduced, which are in accordance through hydrogen engine by means of nominal augment in brake thermal effectiveness. Swaminathan et al. [20] performed the research using acetylene as oil proposed for diesel engine by revenue of HCCI mode with preheated ingestion indict. The obtained brake thermal competence was close to diesel, but the NOx in addition to smoke level was reduced radically and though, $\mathrm{HC}$ emission was augmented.

Nagarajan et al. [21] executed an untried analysis in a diesel engine with hydrogen because oil inside dual fuel form. It has been stated so as to through optimized start of injection, the brake thermal capability was improved. When using the hydrogen in dual fuel mode, the peak force

increases rapidly as well as the have on out gas emissions was considerably condensed. Rao et al.[22 ] examined diesel engine output in dual fuel form by means of introducing a little amount of hydrogen keen on the intake various. At occupied weight, the BTE be equal to diesel through a notable decrease in the tire out gas hotness of smoke emission but the NOx releases were augmented among enhance in high point weight. Tomita et al. [23] examined the initiation of hydrogen within the ingestion port of the particular diesel engine along with diesel and establish that NOx release was reduced due to lean as well as premixed combustion. The releases such as $\mathrm{HC}, \mathrm{CO}$, as well as smoke were as well reduced through a minor add to in brake thermal capability.

It is noted from the literature review that there are fewer works connected to initiation of acetylene through biodiesel. During this present learn, Pongamia methyl ester blend is worn as fuel to replace diesel oil. The tests were performed to conclude the operational independence of diesel engine running with Pongmia methyl ester blend as well as the acetylene was introduced in the ingestion manifold at dissimilar stream rates and the consequences were compared through diesel fuel.

\section{PROPOSED SYSTEM}

\section{A. Preparation of Pongamia oil Methyl ester}

Transesterification is a well-organized method of reducing the thickness of the vegetable oils by the chemical reaction as shown in Figure 1. During this procedure of transesterification triglyceride of vegetable grease (Pongamia oil) react with alcohol (methanol/ethanol) in the number present of method say $\mathrm{NaOH}$ or $\mathrm{KOH}$ as well as form mono ester as well as glycerol. A specified quantity of $1000 \mathrm{ml}$ of Pongamia oil and $450 \mathrm{ml}$ of methanol be in use separately within the round floor flask. At first, 8grams of $\mathrm{NaOH}$ salt is to be was dissolved in a ethanol to form a methoxide solution, then the $1000 \mathrm{ml}$ of Pongamia oil was added to the methoxide solution. These contents were animated awake to $650 \mathrm{C}$ and moved dynamically used for 45 minutes plow the ester was shaped. Then the inside is washed by boiling distilled water and acceptable by resolve overnight inside an unraveling channel. Two layers be formed, the base be water glycerol as well as top was the ester. The base layer is divided by heavy out during a divider regulator fixed less. The invention was animated used for plenty instance by hotness more than $100^{\circ} \mathrm{C}$ for expelling some outstanding water. The consequential methyl ester be a clear fluid with a pale yellow color. The properties of diesel, Pongamia oil as well as its methyl ester are listed within Table 1.

\section{Table- I: Properties of diesel, Pongamia oil and its methyl ester}

\begin{tabular}{|l|l|c|c|}
\hline Properties of diesel & $\begin{array}{l}\text { Diesel } \\
\text { fuel }\end{array}$ & Pongamia oil & POME \\
\hline Diesel Density $\left(\mathrm{kg} / \mathrm{m}^{3}\right)$ & 840 & 912 & 880 \\
\hline
\end{tabular}




\begin{tabular}{|l|c|c|c|c|}
\hline $\begin{array}{l}\text { Kinematic Viscosity } \\
{ }^{\circ} \mathrm{C}(\mathrm{cSt})\end{array}$ & 3.01 & 38.2 & 4.2 \\
\hline $\begin{array}{l}\text { Lower heating } \\
(\mathrm{MJ} / \mathrm{kg})\end{array}$ & value & 42.5 & 32 & 37.25 \\
\hline spark point $\left({ }^{\circ} \mathrm{C}\right)$ & 50 & 270 & 206 \\
\hline Cetane number & 47 & 40 & 52 \\
\hline
\end{tabular}

\section{B. Experimental setup and procedure}

In this study employment, the investigation was accepted away within a single-cylinder stable velocity diesel engine increasing $5.2 \mathrm{~kW}$ of power and it be attached by eddy current dynamometer to apply a brake weight. The fuel run be calculated through noting the instance of permanent amount of diesel captivated with the engine. The oil run rate is calculated by the assist of burette and discontinues watch process. AVL be used to measure the weaken gas emissions and the AVL burn indicator was used to calculate the burn cloudiness. A K category thermocouple is used to calculate the wear out gas heat and inlet and outlet coolant water temperatures. The test engine condition be specified in Table 2.

Table 2: Test engine Specifications

\begin{tabular}{|l|l|}
\hline \multicolumn{1}{|c|}{ Engine } & Specifications \\
\hline Engine Make & Kirloskar, vertical diesel engine \\
\hline Model & TV1, single cylinder, 4S \\
\hline Bore $(\mathrm{mm})$ & 87.5 \\
\hline Stroke $(\mathrm{mm})$ & 110 \\
\hline Rated power(kW) & $5.2 \mathrm{~kW}$ \\
\hline Displacement volume (cc) & 661 \\
\hline Speed(rpm) & 1500 \\
\hline Compression ratio & $17.5: 1$ \\
\hline Fuel injection pressure (bar) & 200 \\
\hline Fuel injection timing & $23^{\circ} \mathrm{bTDC}$ \\
\hline
\end{tabular}

The engine was changed within the direction of execute in the dual oil mode by involving the pipeline from acetylene cylinder to the intake manifold. Acetylene gas be inducted next to through intake air at different flow rates using gas flow meter. To sustain the constant pressure in the pipe line, a pressure regulator was mounted on the acetylene cylinder. In order to avoid any flame flashback, a flame arrester was installed. Acetylene run velocity is calculated by the help of a gas run indicator. A illustration of the experiment engine is exposed in Fig. 1. At first, investigation is performed with POME20 as well diesel at different load conditions. The injection pressure as well as injection timing was kept constant all through the research. Then the test was performed with POME20 and acetylene induction at various flow rates from $11 \mathrm{pm}$ to $4 \mathrm{lpm}$ at all loads in the increment of $1 \mathrm{lpm}$. The fuel flow and emission values were measured for the entire test with and without acetylene induction. The physical and element properties of acetylene gas as well as diesel are specifiedinTable3.

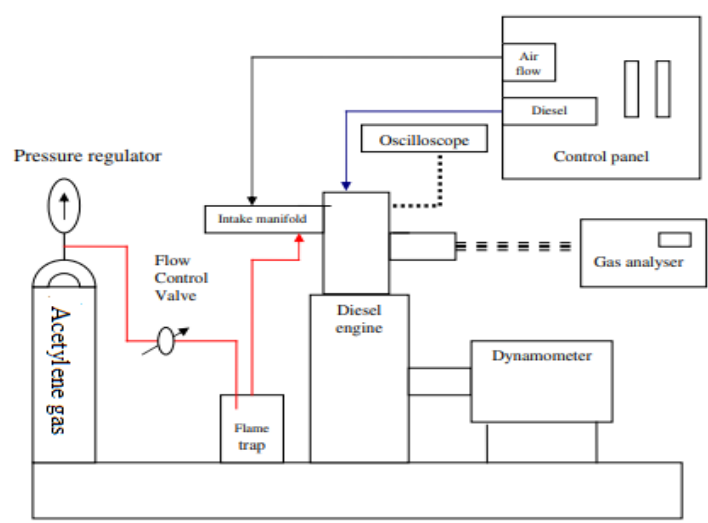

Fig. 1. Schematic of diesel engine test rig

Table 3. Properties of acetylene and diesel

\begin{tabular}{|l|l|l|}
\hline \multicolumn{1}{|c|}{ Properties } & \multicolumn{1}{c|}{ Acetylene } & \multicolumn{1}{c|}{ Diesel } \\
\hline Chemical formula & $\mathrm{C} 2 \mathrm{H} 2$ & $\mathrm{C} 3-\mathrm{C} 10$ \\
& & \\
\hline Density $\left(\mathrm{kg} / \mathrm{m}^{3}\right)$ & 1.092 & 840 \\
\hline Auto ignition temperature $\left({ }^{\circ} \mathrm{C}\right)$ & 302 & 527 \\
\hline Stoichiometric air fuel ratio, $(\mathrm{kg} / \mathrm{kg})$ & 13.2 & 14.5 \\
\hline Lower Calorific Value $(\mathrm{kJ} / \mathrm{kg})$ & 48225 & 42500 \\
\hline Ignition energy $(\mathrm{MJ})$ & 0.019 & -- \\
\hline Flammability Limits $($ Volume \%) & $2.5-81$ & $0.6-5.5$ \\
\hline Adiabatic flame temperature $(\mathrm{K})$ & 2500 & 2200 \\
\hline
\end{tabular}

\section{RESULTS AND DISCUSSION}

\section{A. Brake thermal efficiency}

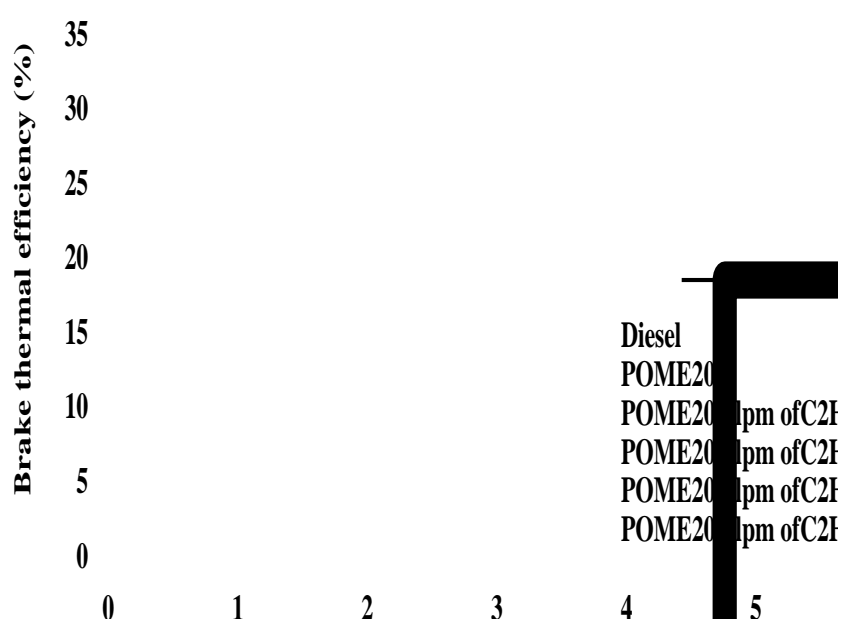

Fig. 2. Brake thermal efficiency variations with BP

Figure 2 shows the development in brake thermal accuracy through during the fluency of diesel brake power of POME20 without and with acetylene gas. The BTE is not the thing but the ratio behind the power of brake to energy input was making in to the engine orderly. There is a decrease in BTE for POME20 is found to be observed when compared to diesel. 
The maximum BTE was obtained, when comes to diesel and POME20 is $30.9 \%$ and $26.8 \%$ ratio, at the range of $100 \%$ load. The drop in BTE for POME20 was expectd from its smaller calorific ratio and poor ignition quality when correlated with diesel fuel [13]. Biodiesel's lower calorific value allows lot of fuel to achieve the equailent power output. With the incorporation of acetylene into the engine, BTE raised for POME20 linearly with increase the levels of acetylene. From BTE for POME20 with 11pm, 21pm, 31pm and $41 \mathrm{pm}$ of acetylene induction at maximum load is $27.8 \%$, $28.6 \%, 29.6 \%$ and $30.2 \%$, respectively. This increase in BTE with acetylene induction with POME20 is expected to high flammability and higher flame accleration of acetylene. These results are matched,when the process of other researchers that deals with diesel/biodiesel from the help of acetylene addition [16].

\section{B. Brake specific fuel consumption}

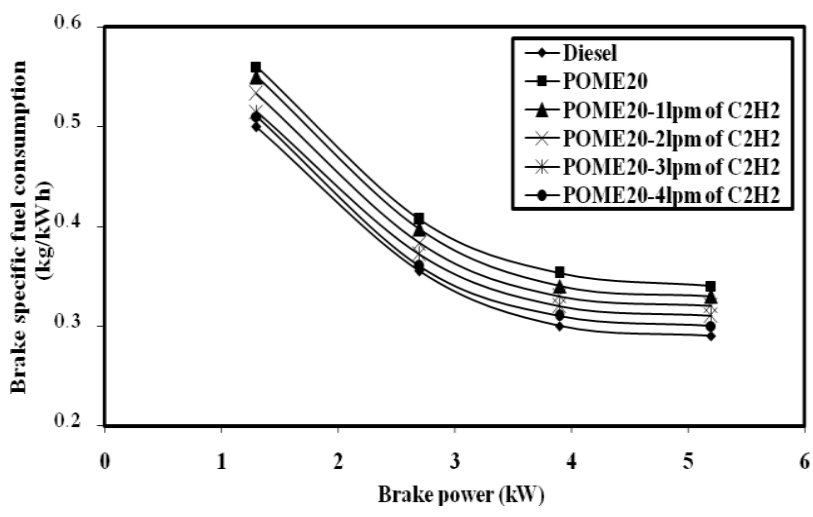

Fig. 3. BSFC variations with BP

Figure 3 shows BSFC against brake power for test fuels without and with acetylene induction. It is observed that the BSEC for POME20 is better than diesel oil on all loads and it be predictable to less important its large viscosity as well as calorific capability from the biodiesel [13]. At 100\% load, BSFC from the diesel and POME20 was $0.29 \mathrm{~kg} / \mathrm{kWh}$ and $0.34 \mathrm{~kg} / \mathrm{kWh}$ manually. From acetylene induction, it is decrease in BSFC especially at full load since of advanced burn velocity of acetylene which leads to better combustion. This is reflected in BTE curve for POME20 with acetylene addition. It is also observed that BSFC of POME20 with acetylene at $11 \mathrm{pm}, 21 \mathrm{pm}, 31 \mathrm{pm}$ and $41 \mathrm{pm}$ flow rates are $0.34 \mathrm{~kg} / \mathrm{kWh}, 0.33 \mathrm{~kg} / \mathrm{kWh}, 0.32 \mathrm{~kg} / \mathrm{kWh}$ and $0.31 \mathrm{~kg} / \mathrm{kWh}$ correspondingly on complete weight.

\section{Exhaust gas temperature}

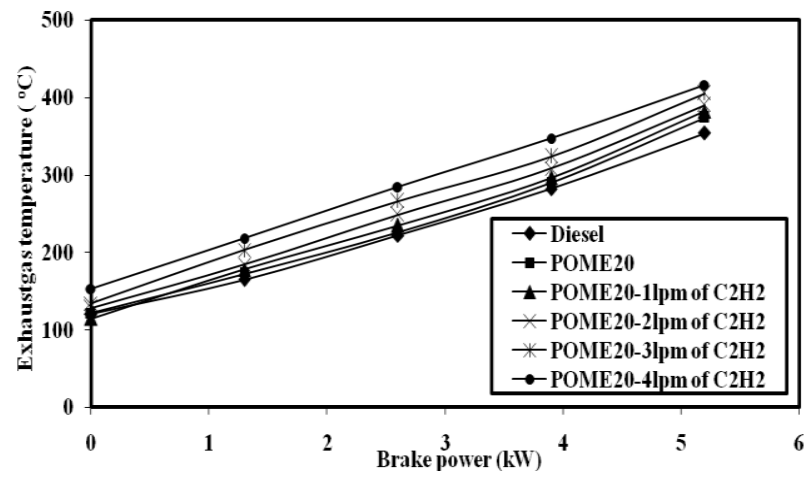

Fig. 4. EGT variations with BP

The engine emissions depend primarily on the temperature of the combustion. The weaken gas heat variations with brake power for the experiment fuels with different flow rates of acetylene induction are represented in Figure 4. It is observed so as to the EGT of diesel as well as POME20 are $354^{\circ} \mathrm{C}$ and $375^{\circ} \mathrm{C}$ respectively at $100 \%$ load, whereas for POME20 with $1 \mathrm{lpm}, 2 \mathrm{lpm}, 3 \mathrm{lpm}$ and $41 \mathrm{pm}$ of acetylene flow rate is $382^{\circ} \mathrm{C}, 390^{\circ} \mathrm{C}, 406^{\circ} \mathrm{C}$ and $416^{\circ} \mathrm{C}$ respectively. The slight increase in EGT with increase in acetylene flow rates may be qualified to the add to in peak burning temperature by the more energy released by the acetylene during combustion process and excess oxygen there in the biodiesel which promotes the oxidation of fuel and air [17].

\section{Carbon monoxide (CO)}

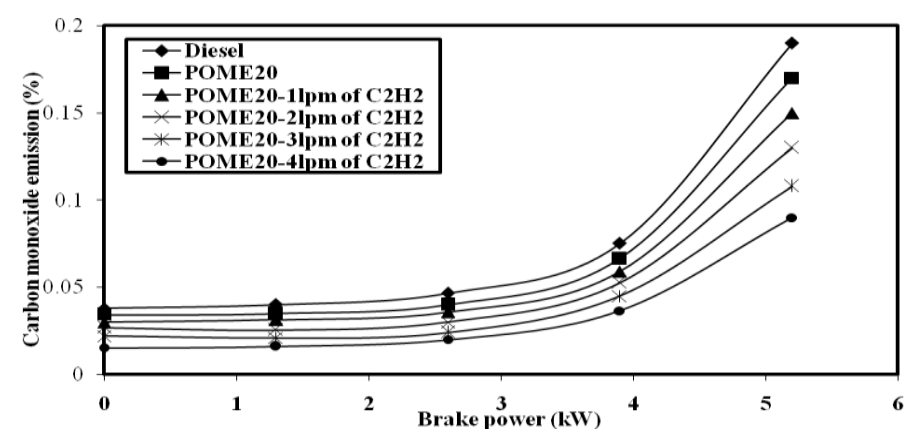

Fig. 5. CO variations with Brake power

The carbon monoxide production variation next to the brake power for the examination fuels are represented in the Figure 5. The $\mathrm{CO}$ emissions are formed in the combustion chamber outstanding to dissimilar factors namely incomplete combustion, lack of oxygen available for combustion [13]. It is practical that POME20 emitted a smaller amount $\mathrm{CO}$ emission when compared to diesel. $\mathrm{CO}$ emission for diesel as well as POME20 is $0.19 \%$ and $0.17 \%$ respectively at utmost load. The decrease in $\mathrm{CO}$ production through biodiesel is credited to the attendance of overload $\mathrm{O}_{2}$ in the biodiesel which promotes the oxidation of $\mathrm{CO}$ into $\mathrm{CO}_{2}$. 
The $\mathrm{CO}$ emission is further reduced with acetylene calculation with POME20. At 100\% load, CO emission with the calculation of acetylene is strong through an average of 21-52\% in comparison when compared with diesel fuel. Combustion is improved with the addition of acetylene so as to increases the peak temperature of combustion, thereby lowering $\mathrm{CO}$ emission levels with all of the fuels [16]. It is also experimental to $\mathrm{CO}$ production of POME20 through acetylene at $11 \mathrm{pm}, 2 \mathrm{lpm}, 31 \mathrm{pm}$ and $41 \mathrm{pm}$ flow rates are 0.15 , $0.13,0.10$ and $0.09 \%$ respectively at full load.

\section{E. Hydrocarbon emission}

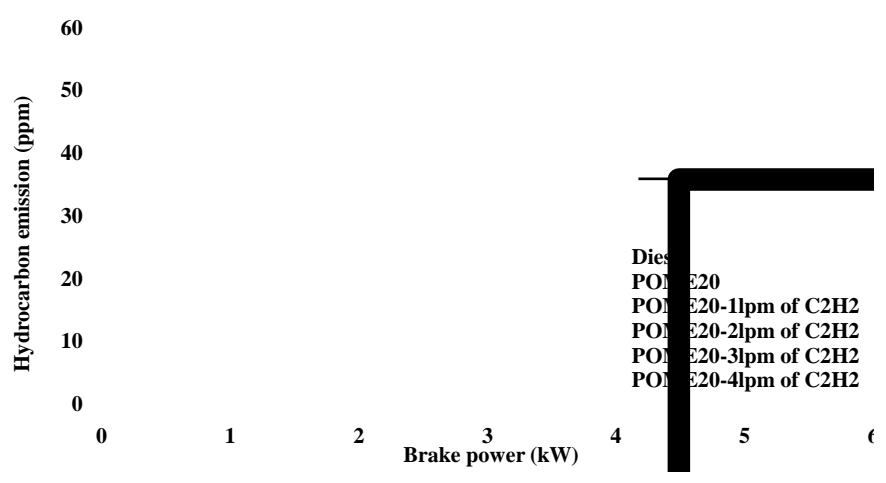

Fig. 6. $\mathrm{HC}$ variations with $\mathrm{BP}$

Figure 6 indicates the difference of $\mathrm{HC}$ production with and brake power for the experiment fuels. Due to over / under mixing, wall impingement and flame quenching on the cylinder walls, $\mathrm{HC}$ emissions are generated in diesel

$\mathrm{HC}$ emissions obtained used for diesel as well as POME20 are 52ppm as well as 48ppm respectively at $100 \%$ load. The condense of $\mathrm{HC}$ emissions by POME20 is owing to the audience of $\mathrm{O}_{2}$ in the molecular arrangement of the fuel, which at higher temperatures oxidizes the $\mathrm{HC}$ emissions into $\mathrm{CO}_{2}$ and $\mathrm{H}_{2} \mathrm{O}$ at $100 \%$ load, This condense in $\mathrm{HC}$ production may be due to $\mathrm{C}-\mathrm{H}$ ratio of inducted acetylene and faster flame of acetylene that enhances the oxidation of biodiesel blend [16].

\section{F. Oxides of nitrogen (NOx)}

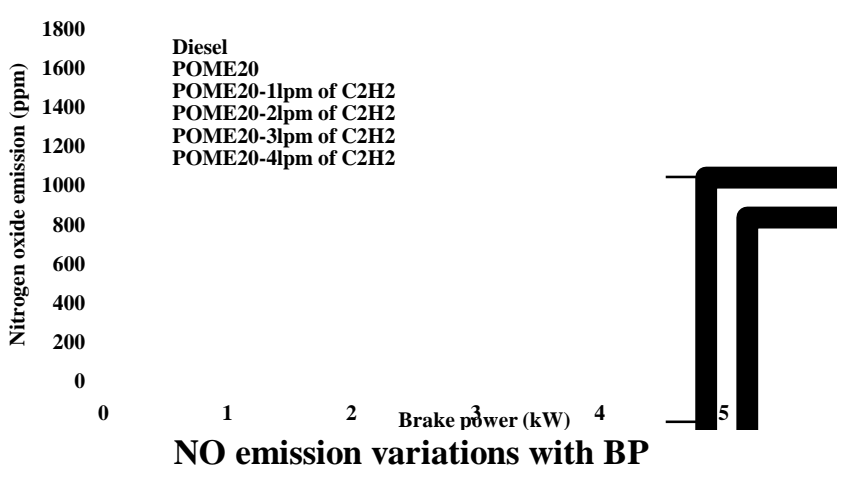

Figure 7 shows the differentiation of NO production against the brake power used for the test fuels with as well as without without acetylene induction at various flow rates beside the engines[13 ].

acetylene instruction. The reason for configuration of NO construction is due the elevated temperature common in the oxygen presence as well as combustion chamber as well as resident time [13]. At 100\% weight, NO production for diesel and POME20 is 1036 ppm as well as 1164 ppm, respectively. Increased NO emissions connected with biodiesel are triggered by the attendance of overload oxygen in its molecular arrangement, that helps to form NO emissions at high combustion temperature [16]. NO is additional improved used for every one examination fuels by the opening of acetylene introduction that increases the peak combustion temperature [26]. NOx emission obtained for POME20 with acetylene induction at 11pm, 21pm, 31pm and $41 \mathrm{pm}$ is $1256 \mathrm{ppm}, 1325 \mathrm{ppm}, 1432 \mathrm{ppm}$ and $1526 \mathrm{ppm}$, respectively at $100 \%$ load.

\section{G. Smoke opacity}

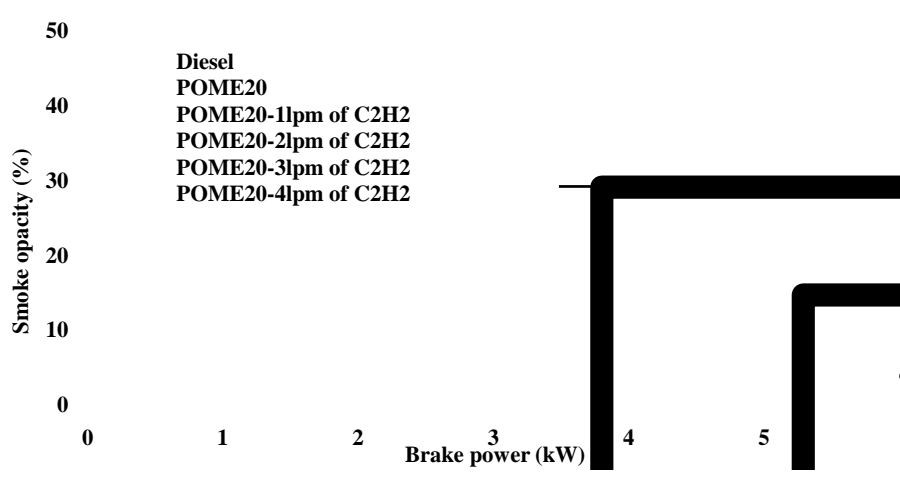

Fig. 7. Smoke opacity variations with $B P$

Figure 8 shows the brake power smoke opacity difference beside smoke opacity used for the examination fuels through as well as devoid of acetylene introduction at different flow rates. High density and viscosity are responsibe for smoke emission formation in engine [44]. In addition, advanced thickness forms additional fuel-rich zone within the burning cavity consequential in inappropriate fuel burning which increases soot formation [13]. It is experimental to on $100 \%$ load, smoke production used for diesel as well as POME20 is $47 \%$ as well as $43 \%$, correspondingly. The clarification used for a smaller amount burn association to diesel owing to overload $\mathrm{O}_{2}$ in biodiesel which oxidizes stain particles on advanced temperatures $[15,16]$. Through the introduction of acetylene, the production of smoke is considerably condensed, mainly on $100 \%$ weight. Smoke opacity obtained for POME20 with acetylene induction at $11 \mathrm{pm}, 2 \mathrm{lpm}, 31 \mathrm{pm}$ and $41 \mathrm{pm}$ is $40 \%, 36 \%, 32 \%$ and $26 \%$, respectively at $100 \%$ load. This decrease in smoke opacity attributed to advanced flame velocity of acetylene as well as overload oxygen available within the biodiesel promotes oxidation of biodiesel blend resulting in decreased smoke emission.

\section{CONCLUSIONS}

The experiment was conducted to learning consequence of acetylene initiation along with POME20 on the presentation

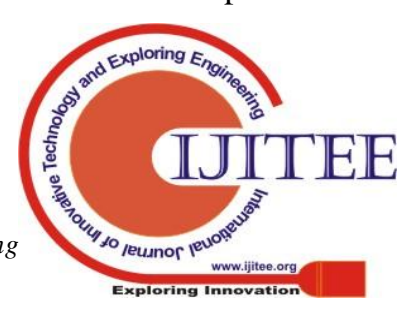


as well as production individuality of diesel engine. The following conclusions are strained as of the investigational outcome:

- At full weight, the BTE for POME20 was decreased through diesel. The acetylene induction at different flow rates of $11 \mathrm{pm}, 2 \mathrm{lpm}, 31 \mathrm{pm}$ and $4 \mathrm{rpm}$ are increased by $1 \%$, $1.8 \%, 2.76 \%$ and $3.4 \%$ respectively. BSFC was also decreased with the calculation of acetylene induction because of higher blaze velocity as well as higher calorific value of aceylene.

- $\mathrm{HC}$ as well as $\mathrm{CO}$ emissions are condensed owing to the excess oxygen satisfied of biodiesel as well as additional condensed through the introduction of acetylene, which improved the combustion of biodiesel blend. The maximum amount of $\mathrm{CO}$ and $\mathrm{HC}$ were decreased by $50 \%$ and $39 \%$ respectively with $4 \mathrm{lpm}$ of acertylene induction along with biodiesel blend.

- The NO production was bigger by $12 \%$ for POME20 as compared in the direction of diesel at $100 \%$ load due to excess $\mathrm{O} 2$ present in biodiesel. Further the NO production was bigger by an regular of $31 \%$ for POME20 with $41 \mathrm{pm}$ of acetelyne induction with biodiesel blend when compared with POME20 at $100 \%$ load.

- Smoke opacity was condensed through biodiesel when compared in the direction of diesel as well as more it is condensed by the adding of acetylene. Smoke emission was greastly condensed with regarding 47\% for POME20 at 4lpm of acetylene addition along with POME20 when compared to POME20.

- On the complete it is done that the addition of acetylene introduction with optimum flow rate of $41 \mathrm{pm}$ along with POME20 based on the improved presentation as well as reduction of harmful weaken gas emissions excluding NOx as of diesel engine

\section{REFERENCES}

1. Agarwal, Avinash Kumar, and Atul Dhar. "Experimental investigations of performance, emission and combustion characteristics of Karanja oil blends fuelled DICI engine." Renewable energy 52 (2013): 283-291..

2. Bannikov, M. G., and R. A. Khan. "Non-edible vegetable oils as a stock for biodiesel in Pakistan: Experimental investigation." J. Intern. Sci. Publ.: Materials, Methods \& Technologies 6.Part 2 (2012): 75-83.

3. Esteban, Bernat, et al. "Characterization of the surface tension of vegetable oils to be used as fuel in diesel engines." Fuel 102 (2012): 231-238.

4. Chauhan, Bhupendra Singh, Naveen Kumar, and Haeng Muk Cho. "A study on the performance and emission of a diesel engine fueled with Jatropha biodiesel oil and its blends." Energy 37.1 (2012): 616-622.

5. Atadashi, I. M., Mohamed Kheireddine Aroua, and A. Abdul Aziz. "High quality biodiesel and its diesel engine application: a review." Renewable and sustainable energy reviews 14.7 (2010): 1999-2008.

6. Chong, Cheng Tung, et al. "Oxygenated palm biodiesel: Ignition, combustion and emissions quantification in a light-duty diesel engine." Energy conversion and management 101 (2015): 317-325.

7. Guan, Chun, et al. "Comparison on the effect of using diesel fuel and waste cooking oil biodiesel as pilot fuels on the combustion, performance and emissions of a LPG-fumigated compression-ignition engine." Applied Thermal Engineering 125 (2017): 1260-1271.

8. Prabhu, L., et al. "Combustion, performance and emission characteristics of diesel engine with neem oil methyl ester and its diesel blends." American Journal of Applied Sciences 10.8 (2013): 810-818.

9. Wamankar, Arun Kumar, and S. Murugan. "Combustion, performance and emission characteristics of a diesel engine with internal jet piston using carbon black-water-diesel emulsion." Energy 91 (2015): 1030-1037.

10. Nazar, J., A. Ramesh, and B. Nagalingam. "Experimental investigation on the performance of karanja oil-hydrogen dual fuel engine."
Proceedings of the 19 th National Conference on IC Engines and Combustion, Annamalai University, Chidambaram. 2005.

11. Saravanan, N., et al. "An experimental investigation on hydrogen as a dual fuel for diesel engine system with exhaust gas recirculation technique." Renewable Energy 33.3 (2008): 422-427.

12. Luijten, C. C. M., and E. Kerkhof. "Jatropha oil and biogas in a dual fuel CI engine for rural electrification." Energy Conversion and Management 52.2 (2011): 1426-1438.

13. Sharma, Prabin K., et al. "Use of acetylene as an alternative fuel in IC engine." Fuel 2.H2 (2012): C8-C20..

14. Elnajjar, Emad, Mohamed YE Selim, and Mohammad O. Hamdan. "Experimental study of dual fuel engine performance using variable LPG composition and engine parameters." Energy conversion and Management 76 (2013): 32-42.

15. Vijayabalan, P., and G. Nagarajan. "Performance, emission and combustion of LPG diesel dual fuel engine using glow plug." JJMIE 2 (2009): 105-110

16. Lakshmanan, T., and G. Nagarajan. "Experimental investigation of timed manifold injection of acetylene in direct injection diesel engine in dual fuel mode." Energy 35.8 (2010): 3172-3178.

17. Lakshmanan, T., and G. Nagarajan. "Performance and emission of acetylene-aspirated diesel engine." JJMIE 3.2 (2009): 125-130..

18. Mahla, S. K., et al. "Study the performance characteristics of acetylene gas in dual fuel engine with diethyl ether blends." International Journal on Emerging Technologies 3.1 (2012): 80-83.

19. Nathan, S. Swami, J. M. Mallikarjuna, and A. Ramesh. HCCI engine operation with acetylene the fuel. No. 2008-28-0032. SAE Technical Paper, 2008.

20. Ashok, V. M. S., and N. I. Khan. "Experimental investigation on use of welding gas (Acetylene) on SI Engine." proceedings of AER Conference, IIT. Vol. 6. 2006

21. Saravanan, N., et al. "Experimental investigation of hydrogen port fuel injection in DI diesel engine." International Journal of Hydrogen Energy 32.16 (2007): 4071-4080..

22. Rao, B. Haragopala, K. N. Shrivastava, and H. N. Bhakta. "Hydrogen for dual fuel engine operation." International Journal of Hydrogen Energy 8.5 (1983): 381-384

23. Tomita, Eiji, et al. Hydrogen combustion and exhaust emissions ignited with diesel oil in a dual fuel engine. No. 2001-01-3503. SAE Technical Paper, 2001

\section{AUTHORS PROFILE}

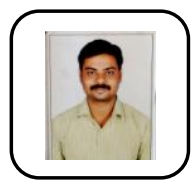

S.Prakash -Research Scholar, Department of Mechanical Engineering Vinayaka Mission Research Foundation

Email:Prakash.mech94@gmail.com

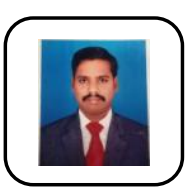

Dr. M.Prabhahar - Professor, Department of Mechanical Engineering Aarupadai Veedu Institute of Technology Vinayaka Mission Research Email:mprabhahar@gmail.com

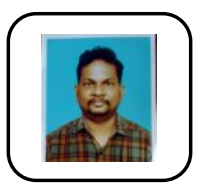

M. Saravana Kumar -Research Scholar Department of Mechanical Engineering Vinayaka Mission Research Foundation Email:sarov003@gmail.com 